\title{
Modelling mechanical properties of the multilayer composite materials with the polyamide core
}

\author{
Krzysztof Talaśka ${ }^{1, *}$, Dominik Wojtkowiak ${ }^{1}$ \\ ${ }^{1}$ Chair of Basics of Machine Design, Poznan University of Technology, Piotrowo 3, 60-965 Poznań, \\ Poland
}

\begin{abstract}
Due to the wide range of application for belt conveyors, engineers look for many different combinations of mechanical properties of conveyor and transmission belts. It can be made by creating multilayer or fibre reinforced composite materials from base thermoplastic or thermosetting polymers. In order to gain high strength with proper elasticity and friction coefficient, the core of the composite conveyor belt is made of polyamide film core, which can be combined with various types of polymer fabrics, films or even rubbers. In this paper authors show the complex model of multilayer composite belt with the polyamide core, which can be used in simulation analyses. The following model was derived based on the experimental research, which consisted of tensile, compression and shearing tests. In order to achieve the most accurate model, proper simulations in ABAQUS were made and then the results were compared with empirical mechanical characteristics of a conveyor belt. The main goal of this research is to fully describe the perforation process of conveyor and transmission belts for vacuum belt conveyors. The following model will help to develop design briefs for machines used for mechanical perforation.
\end{abstract}

Keywords: multilayer polymer composites, polyamide core, conveyor belts, material modelling, Abaqus.

\section{Introduction}

Due to the increasing requirements for the properties of the conveyor and transmission belts, it is necessary to continuously improve them in terms of design, materials and manufacturing technology. Conveyor belts are required to have, above all, appropriate tensile strength, while maintaining adequate stiffness to ensure stability during transport and, at the same time, adequate flexibility that makes it possible to put the belt around small-diameter drive wheels. Flat belts usually have the structure of the multi-layer polymer composite (Fig. 1) and they consist of the core 1, protective gaskets 2 and two covers: bottom (return) 3 and top (load-carrying) $4[1,2]$. Based on the analysis of flat belts available on the market three basic belt types can be distinguished [1-3]:

\footnotetext{
* Corresponding author: krzysztof.talaska@put.poznan.pl

Reviewers: Grzegorz Domek, Bogdan Posiadala
} 
- flexible, light belts whose core is made of polyurethane (sometimes reinforced with polyester fabric), polyvinyl chloride (PVC), fabric or rubber,

- rigid, strong belts whose core is the polyamide layer,

- strong, flexible belts whose polyurethane core is reinforced with aramid fabric (Kevlar) cord.

In most belts, due to beneficial frictional properties, return and load-carrying covers are made of nitrile butadiene rubber (NBR) whose surface structure can be both smooth and rough. In order to obtain a non-flammable layer with a very smooth texture, PVC is also used as material for covers. Protective gaskets are used primarily in rigid belts, and their role is to protect the core from damage and also to improve strength properties. Most often, the role of a gasket is played by a layer of properly woven polyamide fabric, which - in the process of merging belts - is melted into the structure of adjacent layers, ensuring integration of the belt structure [1-3].

In this work, the authors focused on modelling the mechanical properties of rigid, heavy-duty belts whose core is made of a polyamide layer, the role of the gasket is played by polyamide fabric, and the return and load-carrying covers are made of nitrile rubber (NBR). Nitta conveyor belts were used in this research (Fig. 1). For an extensive analysis of belt properties, six belt types were examined, three of which have a polyamide core of the same thickness $(0.5 \mathrm{~mm})$, but differ in stiffness, which is affected by the thickness of the covers along with the gaskets ( $\mathrm{L}$ - light, $\mathrm{M}$ - medium, $\mathrm{XH}$ - extra hard), whereas the remaining belts have increased strength and stiffness (TFL series) with core thickness 0.7 $\mathrm{mm}, 1 \mathrm{~mm}$ and $1.5 \mathrm{~mm}$. The objective of these tests is to model the presented type of material, which will make it possible in further stages of the work to develop the perforation model of this kind of conveyor belt and to determine the effective geometry of the perforating tool using FEM analysis in ABAQUS environment.
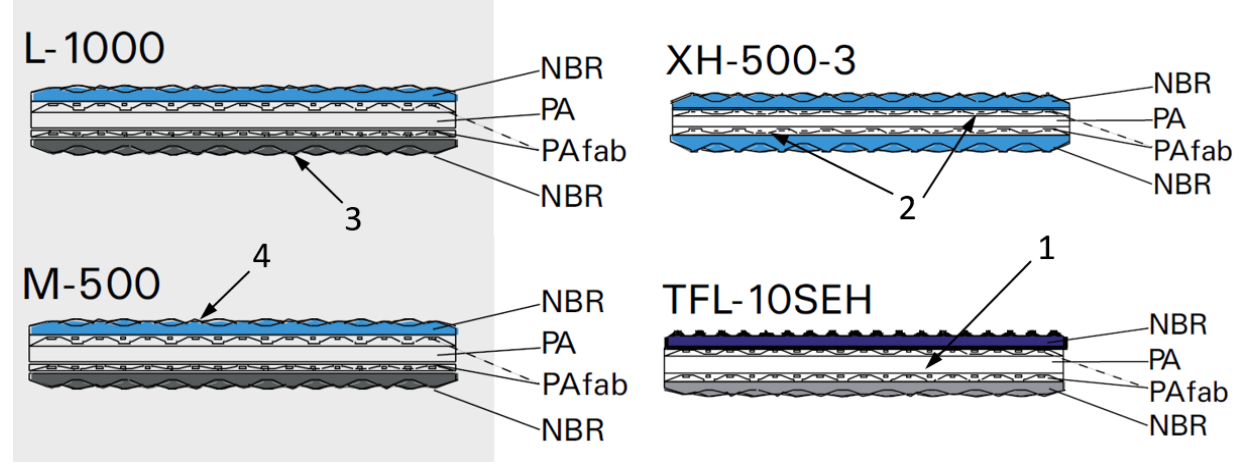

Fig. 1. Nitta PolyBelt ${ }^{\circledR}$ composite conveyor belts with the polyamide core: 1 - core, 2 - gasket, 3 - return cover, 4 - load-carrying cover, NBR - nitrile butadiene rubber, $\mathrm{PA}$ - polyamide, fab - fabric [3]

\section{Methodology of the research}

In order to determine the mechanical parameters necessary to develop the material model of composite materials with polyamide core for each of the six belts (L500, M500, XH500-4, TFL7S, TFL10S and TFL15S), quasi-static tensile testing in a longitudinal direction, compression testing and pure shear testing were performed. For all described testing, MTS Insight testing system with load capacity up to $50 \mathrm{kN}$ and properly adapted equipment was used. Based on the obtained results, it is possible to determine basic material constants (Young's modulus, shear modulus, Poisson's ratio, etc.), necessary to model the material in 
Abaqus. In addition, the results make it possible to analyse the behaviour of the test materials, and the appropriate selection of specimens makes it possible to specify the influence of the thickness of the individual layers on the strength properties of the belt. This approach makes it possible to also apply the model to other belts with a similar structure, but with a different distribution of specific layers.

For tensile testing, a two-shouldered type $\mathrm{B}$ specimen compliant with ISO 527-4:1997 was used. The shape of the specimen ensures that it is not destroyed in grips or adjacent sections and it is recommended for testing fibre- or mat-reinforced plastic composites [4]. The specimen was mounted by its shoulders between the grip plates (Fig. 2a), and subsequently the bolt was strongly tightened. The surfaces of these plates are knurled to prevent the specimen from slipping during the test. Specimens were stretched at a speed of $50 \mathrm{~mm} / \mathrm{min}$, because belt producers use such test conditions in their product data sheets. For each belt type, 5 specimens were stretched and the average characteristics were determined from the obtained results.

Compression testing consisted in compressing the specimen in the form of a disc with a diameter of $10 \mathrm{~mm}$ using a cylindrical pin of the measuring head mounted in the grip of the MTS machine (Fig. 2b). The specimen was placed on a flat steel plate with high stiffness, which eliminated the effect of base plate deformation on the value of compressive stresses. Quasi-static compression testing was performed at a speed of $0.01 \mathrm{~mm} / \mathrm{sec}$ to the value of the compression force $5000 \mathrm{~N}$. Due to the very high repeatability of the results, it was limited to three attempts, which were used to determine the average characteristics of the force relative to displacement.

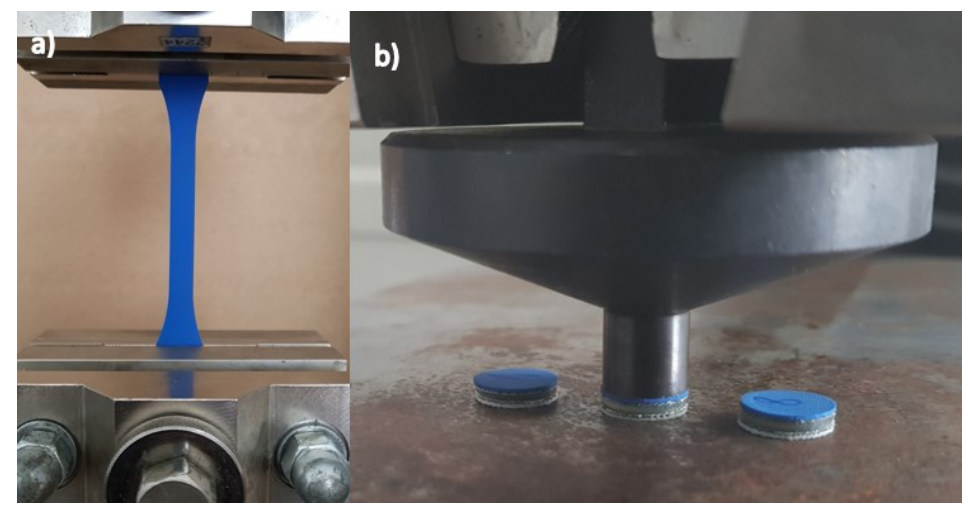

Fig. 2. How the specimen was mounted during testing: a) tensile, b) compression

For shear testing, the station for pure shear of belts presented in Figure 3 and designed by the authors was used. A rectangular specimen 1 with the dimensions $20 \times 100 \mathrm{~mm}$ is sheared by two cutting edges of the moving blade 2 and stationary blade 3 that are made of fast-cutting $64 \mathrm{HRC}$ steel. The moving blade is tightly fitted in the guide plate 4 whose linear motion is provided with two sets of zero backlash linear guides 5, consisting of a guide pole embedded in the base 6 , a guide sleeve embedded in a guide plate and a ball bearing case. This type of guidance ensures the maintenance of appropriate, even very small clearance between the blades. Connecting the guide plate with the grip of the MTS machine 8 is done through the head plate 7 fitted with the bolts to the guide plate. The stationary blade is bolted to the movable support 9 , which provides the ability to adjust the distance between the cutting edges in the range $0 \div 1 \mathrm{~mm}$ thanks to the groove guide system in the base. The second support is the fixed support 10 and both supports are bolted to the base. During the test, the belt specimen is placed on two supports and pressed to them using pressing plates (11) and bolts to ensure proper belt tension while shearing. Because of the 
quasi-static nature of the test, the speed of traverse for the testing machine is $0.5 \mathrm{~mm} / \mathrm{s}$. In the course of the test, the characteristics of the cutting force in the function of displacement are recorded until the specimen is cut through. In addition, the clearance value is measured using a feeler gauge. The tests presented in the were performed for the clearance value $0.05 \mathrm{~mm}$. For each belt type, 5 attempts were made, from which the average characteristics were determined.

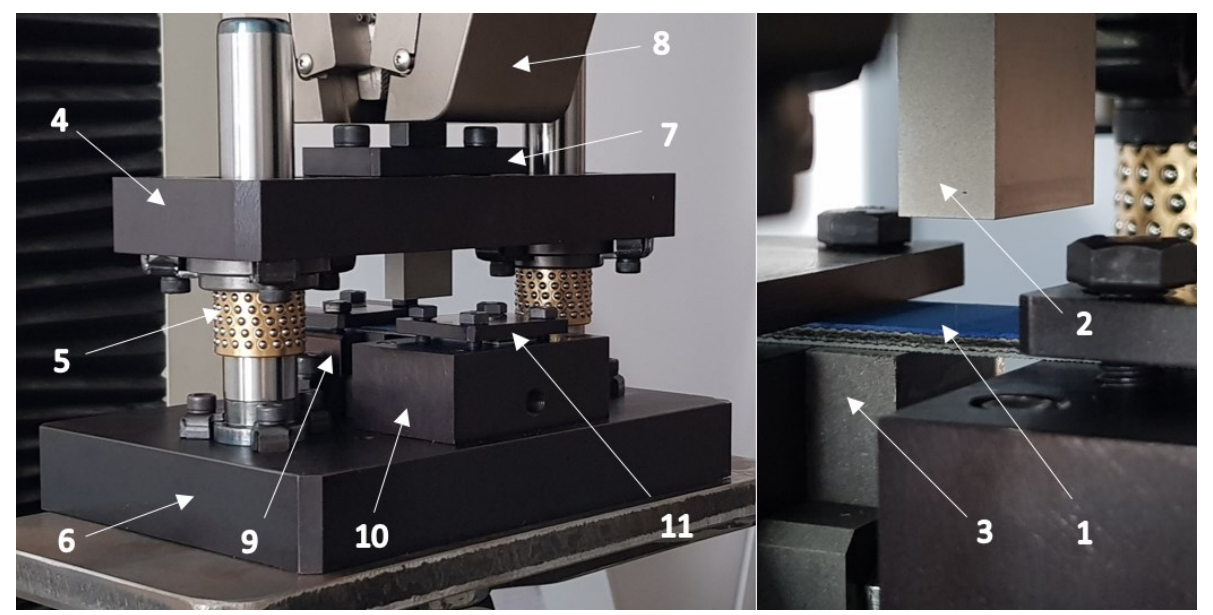

Fig. 3. The station for pure shear of belts and tapes: 1 - specimen, 2 - movable blade, 3 - stationary blade, 4 - guide plate, 5 - linear guides, 6 - base, 7 - head plate, 8 - MTS machine grip, 9 - movable support, 10 - fixed support, 11 - pressing plate

\section{Results of the empirical research}

In order to compare the properties of individual belt types with each other, it is necessary to know the percentage share of a given material in the composite structure. For this purpose, thickness of individual layers was measured using a microscope (Fig. 4) and share ratios $\delta$ were determined for each layer in line with the equations $1 \div 3$. The measurement results are shown in Table 1.

$$
\begin{gathered}
t=t_{P A}+2 t_{P A-f a b}+2 t_{N B R} \\
\delta_{i}=\frac{t_{i}}{t} \\
1=\delta_{P A}+2 \delta_{P A-f a b}+2 \delta_{N B R}
\end{gathered}
$$




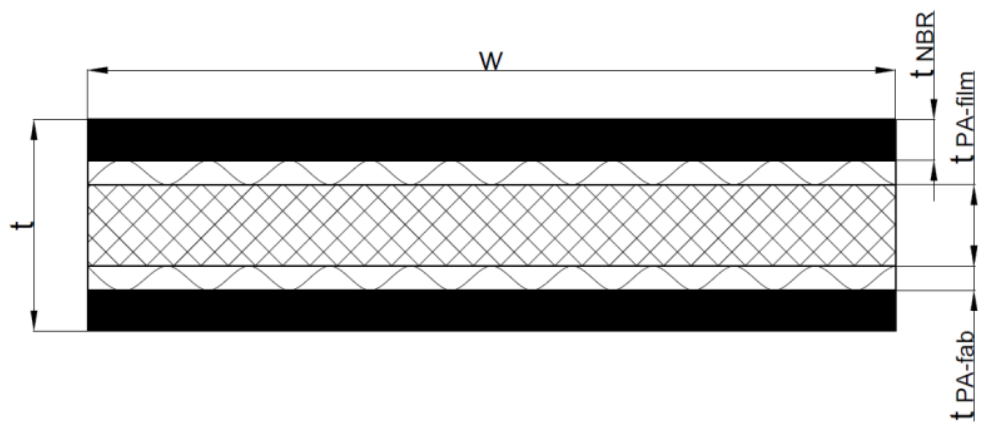

Fig. 4. Cross section of the belt with a polyamide core, together with characteristics measurements schematic

Table 1. Geometrical parameters of the studied conveyor belts

\begin{tabular}{|c|c|c|c|c|c|c|c|}
\hline Belt title & $\begin{array}{c}t \\
{[\mathbf{m m}]}\end{array}$ & $\begin{array}{c}t_{P A-f i l m} \\
{[\mathbf{m m}]}\end{array}$ & $\begin{array}{l}\boldsymbol{t}_{\boldsymbol{P A - f a b}} \\
{[\mathbf{m m}]}\end{array}$ & $\begin{array}{c}t_{N B R} \\
{[\mathbf{m m}]}\end{array}$ & $\begin{array}{l}\delta_{P A} \\
{[-]}\end{array}$ & $\begin{array}{c}\delta_{P A-f a b} \\
{[-]}\end{array}$ & $\begin{array}{c}\delta_{N B R} \\
{[-]}\end{array}$ \\
\hline L500 & 1.55 & 0.5 & 0.3 & 0.225 & 0.3225 & 0.1935 & 0.145 \\
\hline M500 & 2.5 & 0.5 & 0.4 & 0.6 & 0.2 & 0.16 & 0.24 \\
\hline XH500-4 & 4 & 0.5 & 0.4 & 1.35 & 0.125 & 0.1 & 0.3375 \\
\hline TFL7S & 2.4 & 0.7 & 0.4 & 0.45 & 0.292 & 0.167 & 0.1875 \\
\hline TFL10S & 2.6 & 1 & 0.4 & 0.4 & 0.385 & 0.154 & 0.154 \\
\hline TFL15S & 3.1 & 1.5 & 0.4 & 0.4 & 0.484 & 0.129 & 0.129 \\
\hline
\end{tabular}

Figure 5 shows the comparison of the average characteristics of tensile force relative to displacement. A correlation can be observed that the belts whose polyamide core has the same thickness (L500, M500 and XH500-4) have very similar characteristics, whereas a further increase in core thickness causes an increase in the characteristics slope (Young's modulus) and the maximum tensile force, but the breaking point occurs much faster here than for the belts from outside the TFL series. Therefore, it can be seen that increasing core thickness has a beneficial effect on the strength of the belt while significantly increasing its stiffness.

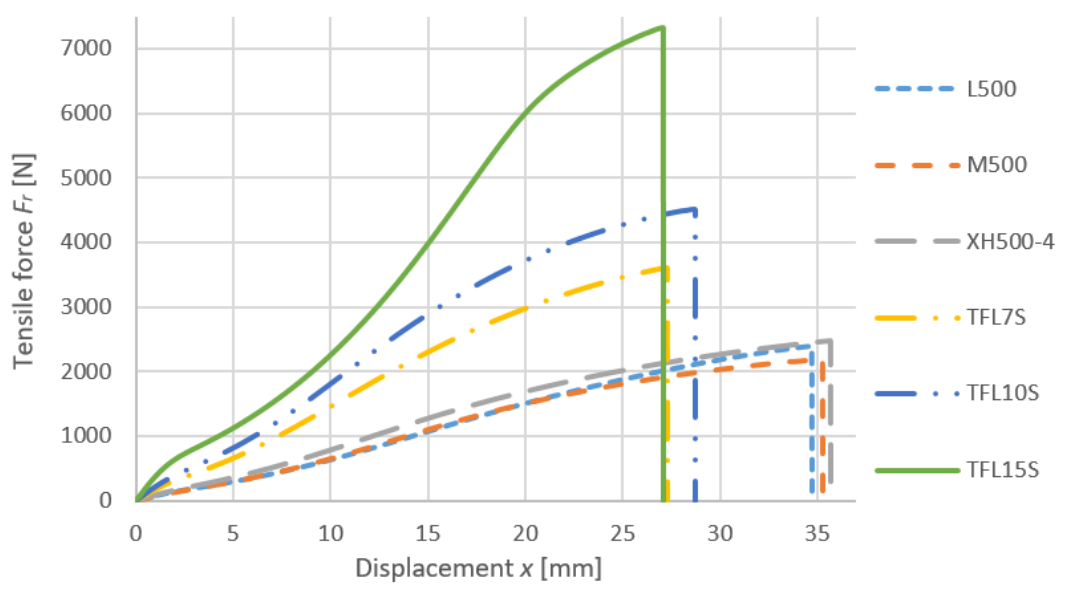

Fig. 5. Correlation of the tensile force relative to displacement $F_{r}(x)$ for 6 tested belt types

Figure 6 shows the comparison of the average characteristics of compression force relative to displacement. Here, the key role is played by the thickness of the nitrile rubber covers. Young's modulus for the TFL series belts and the L500 belt is very similar due to 
a similar share ratio of the rubber layer. The other two belts are characterized by lower Young's modulus, proportionate to their share ratio of the rubber layer.

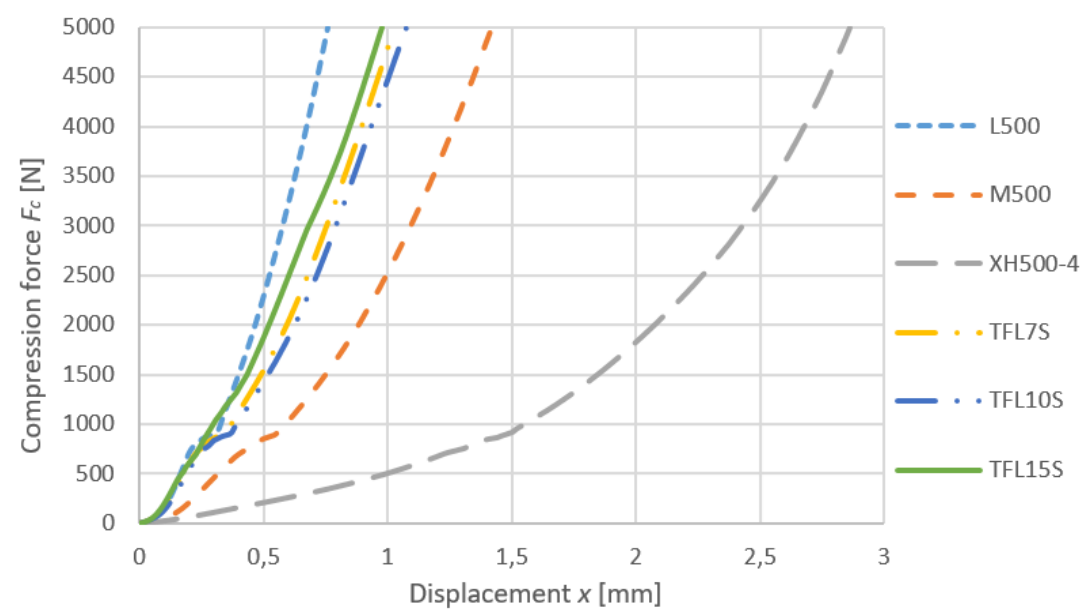

Fig. 6. Correlation of the compression force relative to displacement $F_{c}(x)$ for 6 tested belt types

Figure 7 shows the comparison of the average characteristics of shear force relative to displacement. Here, one can also see the effect of the correlations described for tensile and compression testing, that is the smaller the share of rubber in the belt structure, the faster the force increases, whereas the increase in polyamide code thickness leads to the increase of the shear force.

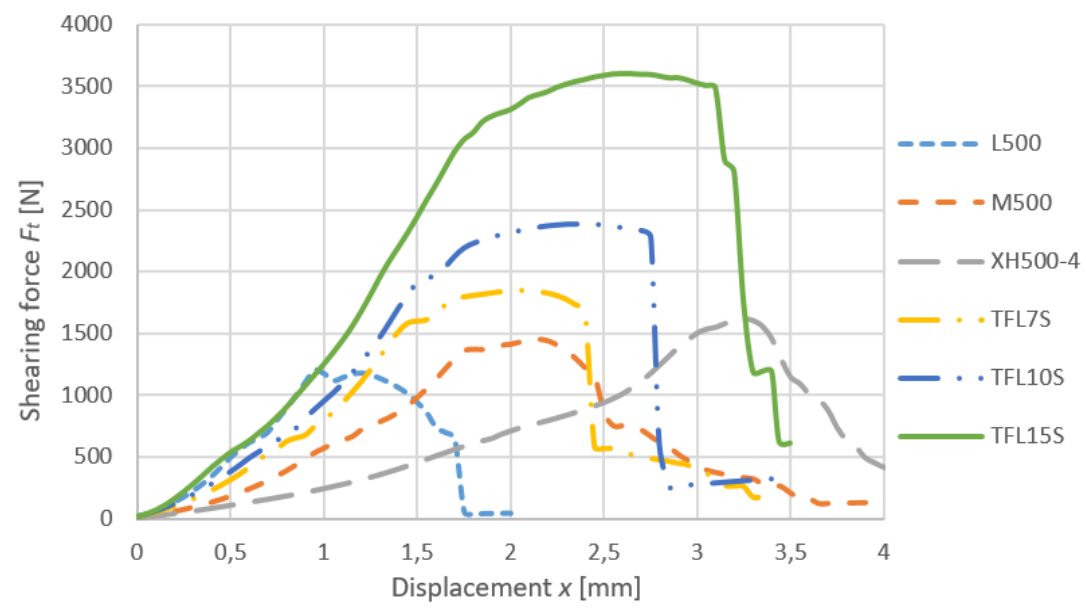

Fig. 7. Correlation of the shear force relative to displacement $F_{t}(x)$ for 6 tested belt types

\section{Modelling mechanical properties of the multilayer material with polyamide core}

In order to determine the elastic mechanical parameters of the belt, it is necessary to chart the stress characteristics in the function of deformation. In the case of the tensile test, deformation is obtained by dividing the displacement of the traverse of the testing machine 
by the length of the measuring section equal to $108 \mathrm{~mm}$. Tensile stresses are determined from the quotient of the tensile force and the cross section of the belt, which is a rectangle with a length of $10 \mathrm{~mm}$ and a width equal to the thickness of the belt t. A sample chart for the tensile test for the TFL10S belt, along with the methodology for determining Young's modulus, is presented in Figure 8. Young's modulus for the compression test was determined in a similar manner (Fig. 9), with the difference being that deformation here is the ratio of displacement to the total thickness of the belt, whereas for determining stresses the circular section with a diameter of $10 \mathrm{~mm}$ is used. In both cases, the base model of reinforced elastic-plastic material was used, in which after achieving certain displacement there is hardening of the material - Young's modulus increases [5].

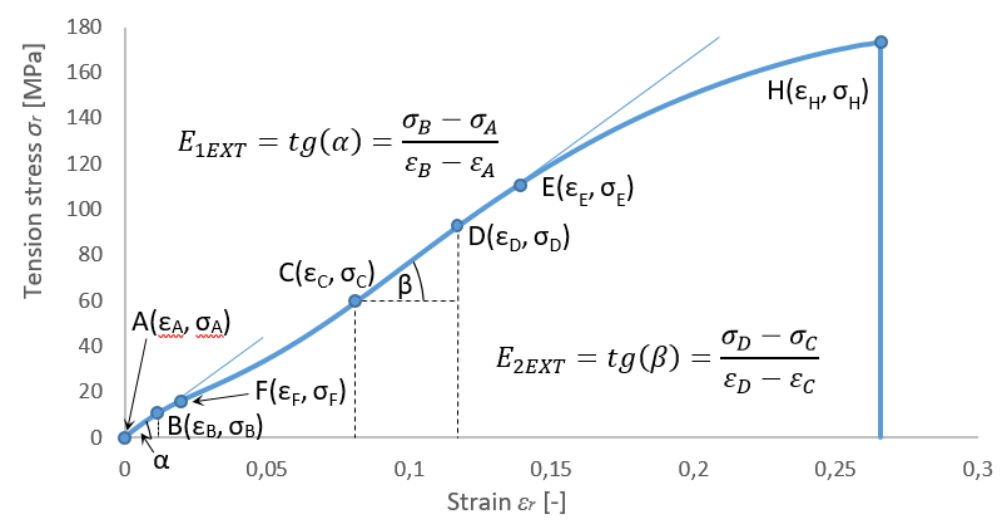

Fig. 8. Correlation $\sigma_{r}\left(\varepsilon_{r}\right)$ for the TFL10S belt, along with the methodology for determining the mechanical parameters

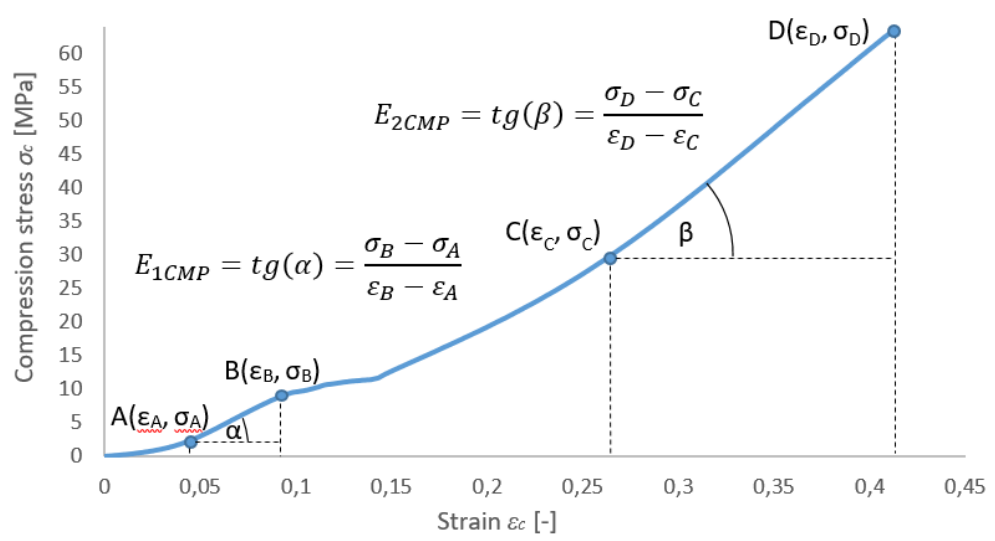

Fig. 9. Correlation $\sigma_{c}\left(\varepsilon_{c}\right)$ for the TFL10S belt, along with the methodology for determining the mechanical parameters

In the case of shear tests, it is necessary to determine the pure shear deformation angle using the correlation 4. After charting the characteristics $(\gamma)$ (fig. 10), shear modulus is determined in an analogous way to Young's modulus in the case of tensile and compression testing. Knowing both moduli, it is possible to determine Poisson's ratio using the correlation 5. It should be noted, however, that this way of modelling materials is subject to significant measuring error, and is used to estimate the parameters of the belt that will be used to perform FEM analysis. The values obtained for the tested belts are presented in Table 2. 


$$
\gamma=\operatorname{arctg}\left(\frac{x}{t}\right)
$$

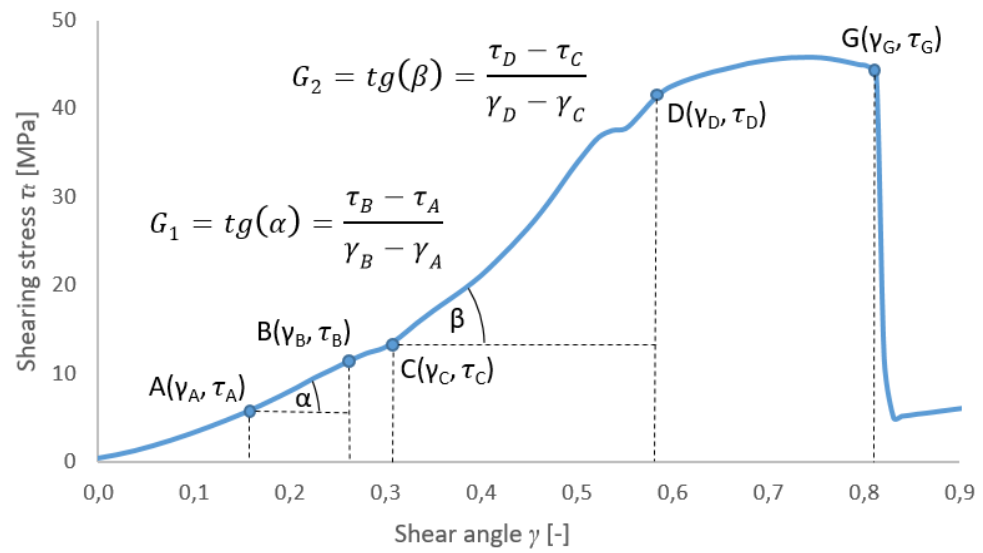

Fig. 10. Correlation $\tau_{t}(\gamma)$ for the TFL10S belt, along with the methodology for determining the mechanical parameters

$$
v=\frac{E}{2 G}-1
$$

Table 2. Elastic mechanical parameters of the tested conveyor belts

\begin{tabular}{ccccccccc}
\hline Belt title & $\begin{array}{c}\boldsymbol{E}_{\boldsymbol{I E X T}} \\
{[\mathbf{M P a}]}\end{array}$ & $\begin{array}{c}\boldsymbol{E}_{\mathbf{2 E X T}} \\
{[\mathbf{M P a}]}\end{array}$ & $\begin{array}{c}\boldsymbol{E}_{\boldsymbol{I C M P}} \\
{[\mathbf{M P a}]}\end{array}$ & $\begin{array}{c}\boldsymbol{E}_{\mathbf{2 C M P}} \\
{[\mathbf{M P a}]}\end{array}$ & $\begin{array}{c}\boldsymbol{G}_{\boldsymbol{1}} \\
{[\mathbf{M P a}]}\end{array}$ & $\begin{array}{c}\boldsymbol{G}_{\boldsymbol{2}} \\
{[\mathbf{M P a}]}\end{array}$ & $\begin{array}{c}\boldsymbol{v}_{\boldsymbol{I}} \\
{[-]}\end{array}$ & $\begin{array}{c}\boldsymbol{v}_{\mathbf{2}} \\
{[-]}\end{array}$ \\
\hline L500 & 537.1 & 618.7 & 116.8 & 223.9 & 41.3 & 92.8 & 0.41 & 0.21 \\
\hline M500 & 320.9 & 390.6 & 82 & 201.2 & 29.2 & 77.2 & 0.4 & 0.3 \\
\hline XH500-4 & 245.9 & 263.4 & 44.1 & 151.8 & 15.4 & 56.2 & 0.43 & 0.35 \\
\hline TFL7S & 768.2 & 765.3 & 141.3 & 222.3 & 50.7 & 90.5 & 0.39 & 0.23 \\
\hline TFL10S & 878.8 & 921.6 & 144.9 & 233.9 & 53.6 & 97.7 & 0.35 & 0.2 \\
\hline TFL15S & 1252.6 & 1365.8 & 177.8 & 289 & 61.8 & 110.4 & 0.44 & 0.31 \\
\hline
\end{tabular}

To model the plastic flow of material and damage mechanics, the Johnson-Cook (J-C) models shown in the formulas 6 and $7[6,7]$ were used. To use this model for FEM analysis, parameters $A, B, C, n, m$ oraz $d_{1} \div d_{5}$ should be determined. Because the tests were performed at room temperature and the nature of the specimen load is quasi-static, the coefficients $C$ and $d_{5}$ related to speed of deformation and $m$ and $d_{5}$ related to material temperature are 0 . Models are therefore simplified to the form presented in the formula 8 .

$$
\begin{gathered}
\bar{\sigma}=\left[A+B\left(\bar{\varepsilon}^{p l}\right)^{n}\right] \cdot\left[1+C \ln \left(\frac{\dot{i}}{\dot{i}}|| \cdot \mid 1-\hat{\theta}^{m}\right]\right. \\
\bar{\varepsilon}_{f}^{p l}=\left[d_{1}+d_{2} \cdot \exp \left(d_{3} \frac{p}{q}\right)\right] \cdot\left[1+d_{4} \cdot \ln \left(\frac{\dot{i}}{\dot{i}}|| \cdot \mid 1+d_{5} \hat{\theta}\right)\right. \\
\bar{\sigma}=A+B\left(\bar{\varepsilon}^{p l}\right)^{n}, \quad \bar{\varepsilon}_{f}^{p l}=d_{1}+d_{2} \cdot \exp \left(d_{3} \frac{p}{q}\right)
\end{gathered}
$$


In order to determine the remaining Johnson-Cook parameters, 3 characteristic points on the chart of the tensile test should be designated - ultimate tensile strength $(\mathrm{E})$, yield point (F) and specimen break point $(\mathrm{H})$ and the point $\mathrm{G}$ on the chart of the shear test, where material damage takes place [7]. Subsequently, the value of engineering stresses and deformations should be converted to the actual values that take into account the change in the specimen section in the plastic range, in line with the formula 9 [8]. In the presented tests, the point $\mathrm{F}$ was assumed to be the point for which the difference between the actual value and the value approximated with the equation of the line $\mathrm{CD}$ was $1 \mathrm{MPa}$. To determine the J-C parameters, the formula 10 was used, with the parameter $\mathrm{n}$ determined for each point after the point $\mathrm{E}$ and then averaged. To determine the parameters of the damage model, it is necessary to know the dimensionless pressure-deviatoric stress ratio, which - for shear - is 0 , for compression $-1 / 3$, and for tensile $1 / 3$ [9]. On this basis, the parameters of the plastic damage model were determined using the correlation 11 . The determined parameters for the tested belts are presented in Table 3.

$$
\begin{gathered}
\varepsilon_{t r}=\ln \left(1+\varepsilon_{\text {eng }}\right), \quad \sigma_{t r}=\sigma_{\text {eng }}\left(1+\varepsilon_{\text {tr }}\right) \\
A=\sigma_{F} \quad n_{i}=\frac{\ln \left[\left(\sigma_{E}-A\right) /\left(\sigma_{i}-A\right)\right]}{\ln \left(\varepsilon_{E} / \varepsilon_{i}\right)} \quad B=\frac{\sigma_{E}-A}{\left(\varepsilon_{E}\right)^{n}} \\
d_{1}=\varepsilon_{E} \quad d_{2}=\gamma_{G}-d_{1} \quad d_{3}=3 \ln \left(\frac{\varepsilon_{H}-\varepsilon_{F}-d_{1}}{d_{2}}\right)
\end{gathered}
$$

Table 3. Parameters of the Johnson-Cook models for the tested belts

\begin{tabular}{ccccccc}
\hline Belt title & $\begin{array}{c}\boldsymbol{A} \\
{[\mathbf{M P a}]}\end{array}$ & $\begin{array}{c}\boldsymbol{B} \\
{[\mathbf{M P a}]}\end{array}$ & $\begin{array}{c}\boldsymbol{n} \\
{[-]}\end{array}$ & $\begin{array}{c}\boldsymbol{d}_{\boldsymbol{1}} \\
{[-]}\end{array}$ & $\begin{array}{c}\boldsymbol{d}_{\mathbf{2}} \\
{[-]}\end{array}$ & $\begin{array}{c}\boldsymbol{d}_{3} \\
{[-]}\end{array}$ \\
\hline L500 & 8.4 & 1213.2 & 1.37 & 0.117 & 0.541 & 3.91 \\
\hline M500 & 4.8 & 518 & 1.16 & 0.160 & 0.55 & 4.9 \\
\hline XH500-4 & 3.8 & 347.7 & 1.14 & 0.107 & 0.575 & 3.78 \\
\hline TFL7S & 11.9 & 1066.4 & 1.18 & 0.133 & 0.652 & 6.41 \\
\hline TFL10S & 13.6 & 1200.1 & 1.17 & 0.127 & 0.686 & 5.98 \\
\hline TFL15S & 18.9 & 2941 & 1.51 & 0.15 & 0.635 & 7.15 \\
\hline
\end{tabular}

On the basis of the obtained results, the model for the approximation of the elastic properties of the belts based on the thickness of their individual layers was determined, shown in Fig. 11. It was observed that in the case of tensile testing Young's modulus depends significantly on the thickness of the polyamide core - quadratic function. Modules $E_{1}$ and $G_{1}$ of the elastic range of the belt depend exponentially on the thickness of the rubber, and modules $E_{2}$ and $G_{2}$ after hardening of the material increase linearly with the increase of the polyamide layer thickness. The following model does not include the effect of the thickness of the gaskets, because the selected belts contain polyamide fabric with

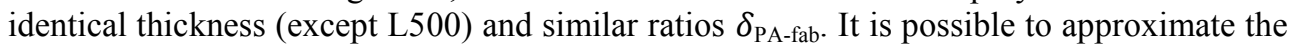
plastic properties of the belt in a similar way or - due to insignificant differences - select the parameters of a comparable belt from Table 3 . 

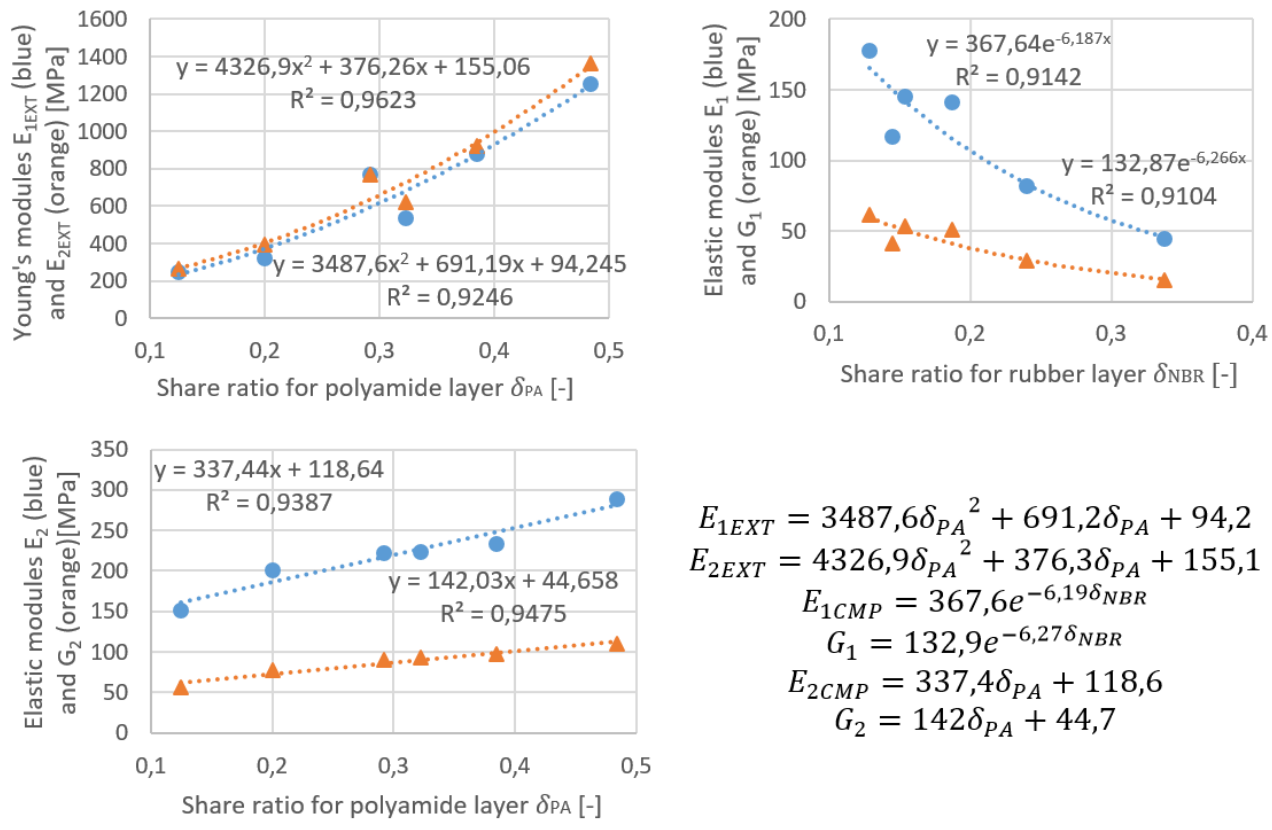

$$
\begin{gathered}
E_{1 E X T}=3487,6 \delta_{P A}{ }^{2}+691,2 \delta_{P A}+94,2 \\
E_{2 E X T}=4326,9 \delta_{P A}{ }^{2}+376,3 \delta_{P A}+155,1 \\
E_{1 C M P}=367,6 e^{-6,19 \delta_{N B R}} \\
G_{1}=132,9 e^{-6,27 \delta_{N B R}} \\
E_{2 C M P}=337,4 \delta_{P A}+118,6 \\
G_{2}=142 \delta_{P A}+44,7
\end{gathered}
$$

Fig. 11. Model for the approximation of the elastic mechanical properties of composite belts with polyamide core

\section{FEM analyses}

In order to verify the accuracy of the derived model of the mechanical belt with a polyamide core, FEM analyses were performed, aimed at recreating the tensile and compression tests using the obtained parameters for the TFL10S belt. Both analyses were performed with the Abaqus/Explicit module. The change of Young's modulus was obtained using the VUSDFLD subroutine, which caused the hardening of the material beyond a given stress value. Because of the quasi-static nature of the study, in order to reduce calculation time, the Mass Scaling feature was used during the simulation. It is justified in the case of a negligibly small impact of inertia forces on the results of the calculated values [6].

In the model of the tensile test, a two-shouldered specimen was divided into two gripping sections and a measuring section using the partition. The lower gripping section was stripped of all degrees of freedom with the boundary condition (BC) ENCASTRE. A reference point was created on the top gripping section and attached to all its surfaces, and kinematic excitation with speed $50 \mathrm{~mm} / \mathrm{min}$ in the direction of the specimen axis was obtained using BC Velocity applied to this point. The results of the analysis are shown in Figure 12.

In the case of the shear test model, all the elements except the belt were modelled as rigid by attaching Rigid Body to reference points located on each of them. The support, pressing plates and the stationary blade were stripped of all degrees of freedom, whereas kinematic excitation of the moving blade at the speed of $0.5 \mathrm{~mm} / \mathrm{s}$ was achieved through $\mathrm{BC}$ Velocity applied to the reference point to which it is rigidly attached. From this point, the reaction force present in the cutting process was also recorded. Because of the complexity of the model, the local control of the grid was used in order to thicken it in the 
shear plane, which made it possible to obtain more accurate results with a minimal extension of the calculatation time. Sample results of the analysis are shown in Figure 13.
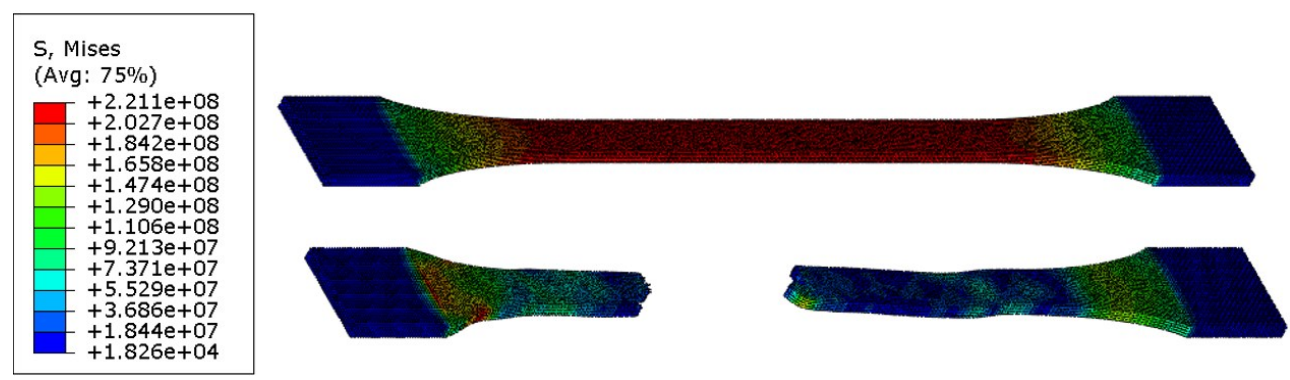

Fig. 12. Results of the FEM analysis of the tensile test for the belt TFL10S

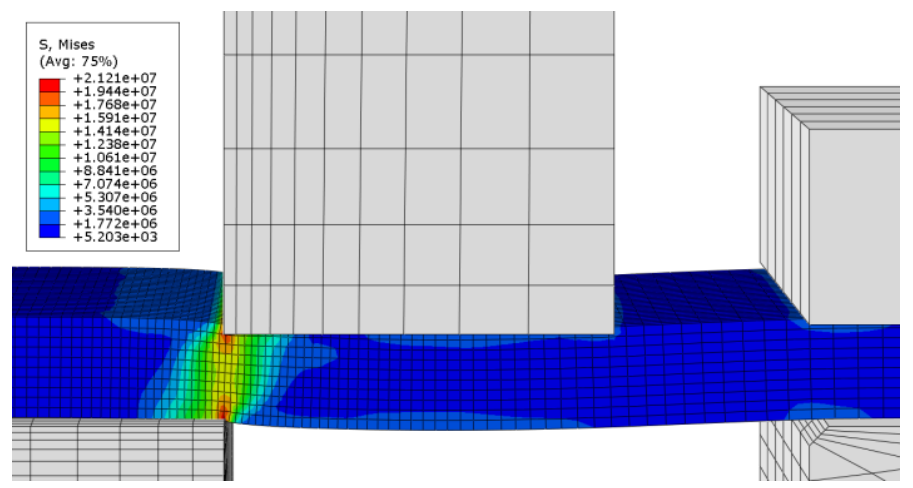

Fig. 13. Results of the FEM analysis of the shear test for the belt TFL10S

For comparison of the results of FEM analyses and experimental research, the characteristics presented in Figures 14 and 15 were charted. It can be observed that the difference between the values of the most important parameters, that is the values where damage occurs, does not exceed $15 \%$. However, there are visible differences in the course of the characteristics, which may introduce errors when modelling the perforation process.

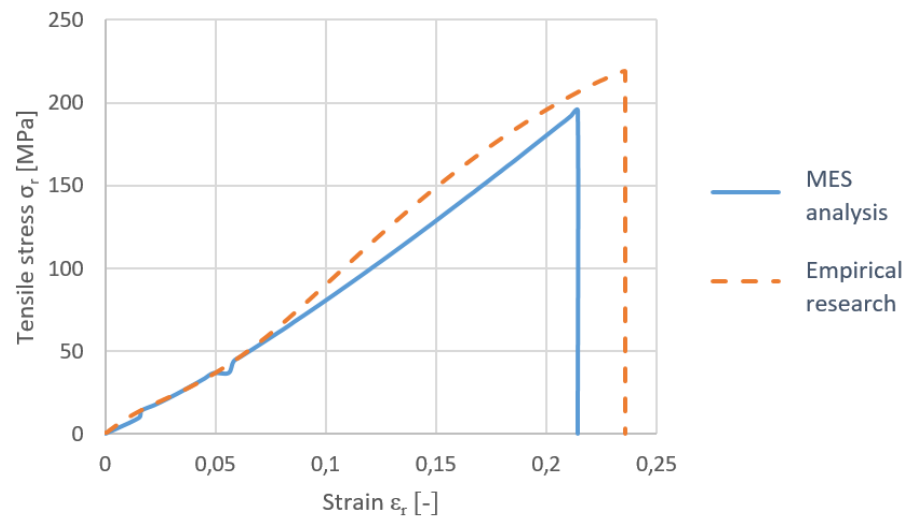

Fig. 14. Comparison of the results of empirical research and FEM analysis for the tensile test 


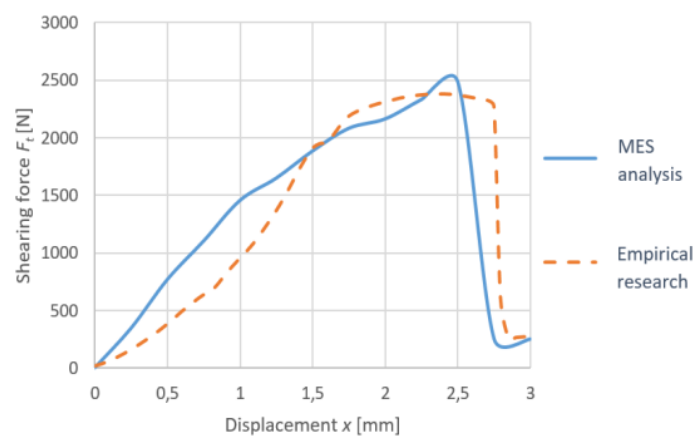

Fig. 15. Comparison of the results of empirical research and FEM analysis for the tensile test

\section{Conclusions}

Based on the results of research and FEM analysis presented in this work, it can be said that the developed model makes it possible to approximate the mechanical parameters of belts with polyamide core with $15 \%$ accuracy. Thanks to this, the model becomes useful for comparative analyses of different geometries of perforating tools, which - together with relevant empirical verification studies - will make it possible to develop effective blade geometry. This model, however, is insufficient to fully model the complex process of perforation because it does not take into account many factors, such as temperature or deformation speed. In further research, it is planned to extend the research to refine the model.

\section{References}

1. M. Hardygóra, Taśmy przenośnikowe. Wydawnictwo Naukowo-Techniczne, Chapter 1 and 2, Warszawa (1999)

2. L. Gładyszewicz, Przenośniki Taśmowe - teoria $i$ obliczenia. Wydawnictwo Politechniki Wrocławskiej (2003)

3. Wilhelm Herm. Müller, Nitta Industries - polish catalog. www.whm.pl (Access date: 06.07.2017)

4. S. Ochelski, Metody doświadczalne mechaniki kompozytów konstrukcyjnych. Wydawnictwo Naukowo-Techniczne, Warszawa (2004)

5. C. Yu, R. Yang et al., Relationships between the work recovery ratio of indentation and plastic parameters for instrumented spherical indentation. MRS Comunications 5 (1), 89-94 (2015)

6. Abaqus User's Manual, Version 6.13-2, Dassault Systémes Simulia Corp., Providence, Rhode Island, USA (2013)

7. Y. Zhang, J.C.Outerio, T. Mabrouki, On the Selection of Johnson-cook Constitutive Model Parameters for Ti-6Al-4 V Using Three Types of Numerical Models of Orthogonal Cutting. Procedia CIRP 3, 112-117 (2015).

8. I. Faridmehr, M.H.Osman et al., Correlation between Engineering Stress-Strain and True Stress-Strain Curve. American Journal of Civil Engineering and Architecture 2 (1), 53-59 (2014)

9. S. Kut, A simple method to determine ductile fracture strain in a tensile test of plane specimen's. Metallurgy 49 (4), 295-299 (2010) 